\title{
Amigos Imaginários: Contribuições para o Desenvolvimento Infantil
}

\author{
Natália Benincasa Velludo, \& Débora de Hollanda Souza ${ }^{1}$ \\ ${ }^{1}$ Universidade Federal de São Carlos, São Carlos, SP, Brasil
}

\begin{abstract}
RESUMO - A criação de amigos imaginários é uma manifestação de faz de conta comum na infância, que tem sido pouco explorada na literatura psicológica. A presente pesquisa teve como objetivo investigar a relação entre esse fenômeno e o desenvolvimento da linguagem e da cognição social. Quarenta crianças entre 6 e 7 anos (18 com amigos imaginários e 22 sem) foram avaliadas por medidas de teoria da mente, compreensão emocional e vocabulário, bem como entrevistas para explorar o engajamento em fantasia. Uma entrevista sobre as experiências de fantasia da criança foi feita com 11 pais/ responsáveis. Os resultados sugerem que o fenômeno se associa a um vocabulário receptivo mais desenvolvido e não é indicativo de déficits em desenvolvimento sociocognitivo.
\end{abstract}

PALAVRAS-CHAVE: amigo imaginário, brincar de faz de conta, crianças

\section{Imaginary Companions: Contributions to Child Development}

\begin{abstract}
The creation of imaginary companions is a frequent manifestation of pretend play in childhood, which has been little explored in psychological literature. The goal of the present research was to investigate the relation between this phenomenon and language and social cognitive development. Forty children between 6 and 7 years of age (18 with imaginary companions and 22 without) were assessed by theory-of-mind, emotion understanding and vocabulary measures, as well as by interviews exploring engagement in fantasy. An interview on children's fantasy experiences was conducted with 11 parents/caretakers. Results suggest that the phenomenon is associated with a more developed receptive vocabulary and is not indicative of deficits in social cognitive development.
\end{abstract}

KEYWORDS: imaginary companion, pretend play, children

Uma manifestação de fantasia comum na infância é a criação de amigos imaginários, um tipo de faz de conta especialmente duradouro, que envolve personagens (pessoas, animais ou criaturas) cujas identidades permanecem estáveis ao longo de meses ou mesmo anos. Há dois diferentes tipos de companhia imaginária: aquele em que o papel criado é projetado sobre algum objeto de apoio, como um brinquedo, e o chamado de invisível, que não conta com nenhum suporte físico. De fato, tais criações são invocadas com tanta regularidade no dia a dia da criança, que se tornam uma forma de companhia para ela (Harris, 2000; Taylor, 1999).

Muitos pais e profissionais, entretanto, preocupam-se com possíveis efeitos negativos da criação de amigos imaginários em virtude das características particulares desse faz de conta, mais especificamente, sua grande duração, frequência e o fato de que ele é acompanhado de um envolvimento emocional da criança. Talvez motivados por essa mesma preocupação, os primeiros estudiosos do fenômeno chegaram a conclusões pouco animadoras, destacando, por exemplo, uma possível associação com problemas emocionais e sociais. No entanto, essas primeiras pesquisas apresentavam problemas metodológicos, tais como a seleção de amostras não-aleatórias e a ausência de grupos de comparação. Mais recentemente, pesquisas psicológicas, conduzidas com maior rigor metodológico, têm indicado que a criação de amigos imaginários é não só um fenômeno comum, mas um hábito saudável (Harris, 2000; Taylor, 1999; Taylor \& Mottweiler, 2008).

*E-mail: nataliabvelludo@gmail.com 


\section{AMIGOS IMAGINÁRIOS E DESENVOLVIMENTO INFANTIL}

Taylor e Mannering (2007) defendem que a pesquisa sobre amigos imaginários tem muito a nos ensinar sobre as capacidades cognitivas humanas e o desenvolvimento da imaginação, em especial, porque há mais continuidades do que descontinuidades entre o pensamento infantil e adulto. Na literatura, o estudo da criação de companhias imaginárias foi tradicionalmente limitado a crianças de idade pré-escolar, contudo, dados mais recentes evidenciam que o fenômeno é frequente também nos anos escolares (Bouldin \& Pratt, 2001; Hoff, 2005b; Mathur \& Smith, 2008; Taylor, Carlson, Maring, Gerow, \& Charley, 2004). De todo modo, apenas uma minoria das crianças passa a interagir com seres imaginários no final da infância ou mesmo no início da adolescência (Seiffge-Krenke, 1997; Taylor, 1999).

Em geral, os pais de pré-escolares costumam saber quando seus filhos possuem companhias imaginárias, pois as próprias crianças produzem relatos elaborados sobre os seus amigos e, ao menos implicitamente, convidam os pais a interagirem com suas criações. Ainda assim, há pais que afirmam desconhecer o uso desse faz de conta pelos filhos, e esse desconhecimento parece ser mais frequente quando os filhos já terminaram a Educação Infantil (Gleason, 2004; Taylor, 1999). Taylor (1999) afirma que apenas uma pequena parte $(20 \%)$ dos pais de crianças entre 6 e 7 anos com tais companhias sabem da existência dos mesmos.

Entre os pais que reconhecem esse tipo de fantasia nos filhos, há uma grande variação no que diz respeito à reação e interpretação do fenômeno. Enquanto alguns pais possuem uma visão muito positiva sobre o fenômeno, inclusive fazendo associações com o desenvolvimento da inteligência e da criatividade, outros possuem visões muito negativas, e temem que a manifestação do fenômeno se associe a problemas emocionais, risco de desenvolver distúrbios psicológicos e dificuldade em distinguir realidade de fantasia (Taylor, 1999; Taylor \& Carlson, 2000).

É importante destacar, no entanto, que embora as crianças ajam como se as suas criações fossem reais, quando indagadas sobre o status de realidade dos seus amigos, elas são capazes de explicitar que eles são apenas fruto da imaginação, demonstrando não haver confusão entre realidade e fantasia (Taylor, Shawber, \& Mannering, 2009). Segundo a literatura, uma função importante desse tipo de faz de conta, além de ser fonte de diversão, é fornecer companhia e apoio emocional (Hoff, 2005a; Taylor, 1999). Além disso, os amigos imaginários parecem ajudar a criança a lidar com problemas emocionais ou medos (Taylor, 1999), podendo inclusive promover resiliência (Taylor, Hulette, \& Dishion, 2010). O fenômeno tem sido associado ainda a aspectos muito positivos do desenvolvimento, como: (a) criatividade (e.g., Hoff, 2005b), (b) sociabilidade ou competência social (Gleason, 2002; Hoff, 2005a; Manosevitz, Prentice,
\& Wilson, 1973) e (c) competência narrativa (Taylor, Cartwright, \& Carlson, 1993; Trionfi \& Reese, 2009).

De forma mais abrangente, a brincadeira simbólica de qualquer natureza tem sido relacionada a ganhos em habilidades importantes para a criança, tais como monitoramento, tomada de decisão, revezamento, reciprocidade, linguagem e interação social (cf. Preissler, 2006). O faz de conta também parece contribuir para o desenvolvimento da cognição (Harris, 2000). Em especial, a relação da brincadeira simbólica com a teoria da mente tem sido largamente estudada (Harris, 2006).

A teoria da mente subjaz a habilidade de explicar, predizer e interpretar a ação e o discurso, por meio da atribuição de estados mentais, como desejos, crenças, intenções e emoções, a si próprio e aos outros constituindo-se o cerne da autorreflexão e da compreensão social (Astington \& Hughes, 2013). Assim, o termo referese a esse conhecimento popular, ou ingênuo, que crianças e adultos desenvolvem sobre o funcionamento da mente (Carpendale \& Lewis, 2006).

Diferentes estudos evidenciam que as crianças que se engajam mais em jogo de papéis são mais habilidosas em compreender estados mentais, apresentando melhores desempenhos em testes que exigem a apreciação da perspectiva de terceiros no que se refere a emoções, crenças e desejos (Astington \& Jenkins, 1995; Jenkins \& Astington, 2000; Taylor \& Carlson, 1997; Youngblade \& Dunn, 1995). Apesar das evidências de uma correlação, a direção da relação que se estabelece entre o faz de conta e a teoria da mente é algo ainda bastante discutido na literatura (Smith, 2002; Sperb \& Carraro, 2008).

Interessados nas possíveis contribuições da fantasia para a cognição social, Taylor e Carlson (1997) investigaram se o alto engajamento em fantasia estaria associado ao desempenho em tarefas de teoria da mente em crianças de 3 e 4 anos. As diferenças individuais em fantasia eram acessadas por meio de: (a) identificação da criação de amigos imaginários; (b) personificação (e.g., a criança se identifica como o Batman); (c) uma pontuação resultante da combinação de dados obtidos em entrevistas e medidas comportamentais. De fato, cada medida de fantasia se correlacionava significativamente com as pontuações obtidas nas tarefas de teoria da mente, independentemente de inteligência verbal, para as crianças de 4 anos.

Tal associação, no entanto, não é um consenso na literatura, uma vez que Davis, Meins e Fernyhough (2011) não reproduziram esse resultado em seu estudo, no entanto, as crianças com amigos imaginários se saíam melhor na tarefa de julgar quem teria acesso a aspetos internos delas (i.e., pensamentos, sonhos, desejos e sensações). De forma semelhante, Fernyhough, Bland, Meins e Coltheart 
(2007) não encontraram uma associação entre ter amigos imaginários e o desempenho em uma tarefa particular de teoria da mente. A tarefa avaliava a compreensão de que a consciência permanece, ainda que na ausência de dicas perceptuais externas. Ainda assim, os achados de Gleason, Jarudi e Cheek (2003) sugerem que o fenômeno se associa a uma cognição social mais sofisticada no início da vida adulta. Taylor e Mannering (2007) acreditam que o jogo de papéis com amigos imaginários se relaciona a uma maior habilidade de adotar a perspectiva de outros e, assim, considerar como as representações mentais estão associadas à realidade, apesar de diferirem dela.

A criação de amigos imaginários também tem sido associada a diversas vantagens linguísticas. Mais especificamente, quando comparadas a pares que não se engajam nesse tipo de faz de conta, as crianças com amigos imaginários apresentam: (a) habilidades verbais mais maduras, entre os 4 e 8 anos (Bouldin, Bavin, \& Pratt, 2002); (b) produção de narrativas mais ricas, aos 5 anos, mesmo controlando-se vocabulário (Trionfi \& Reese, 2009); (c) além de maior competência em comunicação referencial, em que a tomada de perspectiva é requerida, entre crianças de 4 a 6 anos (Roby \& Kidd, 2008).

Em uma revisão sistemática da literatura sobre amigos imaginários, Velludo e Souza (2015) destacam, no entanto, que embora a brincadeira simbólica tenha sido amplamente estudada no Brasil, o número de pesquisas nacionais sobre a criação de amigos imaginários é ainda muito escasso (Bittencourt \& Blanco, 1996; Tavares \& Pinheiro, 1989). De fato, a maior parte da literatura sobre amigos imaginários provém dos EUA, o que se deve em especial às contribuições de Marjorie Taylor e seus colaboradores (e.g., Taylor \& Carlson, 1997; Taylor et al., 1993; Taylor et al., 2010). Ainda assim, há várias questões relevantes que permanecem por ser investigadas e que podem contribuir para uma melhor compreensão da função desse tipo particular de fantasia no desenvolvimento emocional e cognitivo infantil (Taylor et al., 1993).

Em particular, mais estudos investigando possíveis relações entre a criação de amigos imaginários e o desenvolvimento de competências sociocognitivas e linguísticas precisam ser conduzidos. $\mathrm{O}$ presente trabalho visou, portanto, contribuir nessa direção investigando este tipo de faz de conta em uma amostra de crianças escolares, tendo sido a primeira pesquisa brasileira a investigar a sua relação com o desenvolvimento sociocognitivo e a linguagem.

Os objetivos principais da presente pesquisa foram: (a) explorar as características de tais criações de fantasia em uma amostra de crianças escolares brasileiras; (b) investigar possíveis relações entre a criação de amigos imaginários e o desenvolvimento sociocognitivo infantil, mais especificamente, testar possíveis diferenças entre dois grupos de crianças (com amigos imaginários x sem amigos imaginários) no desempenho em diferentes tarefas de teoria da mente, em um teste de compreensão emocional e em uma medida de vocabulário receptivo.

\section{MÉTODO}

\section{Participantes}

Participaram do presente estudo 40 crianças em idade escolar (21 meninas e 19 meninos) e 11 responsáveis (mães e uma avó). Os participantes foram recrutados em uma escola de Ensino Fundamental da rede estadual de um município do estado de São Paulo. A amostra contou com 16 crianças de 6 anos $(M=6 ; 7, D P=1,98)$ e 24 crianças de 7 anos $(M=$ $7 ; 4, D P=3,50)$. Os participantes foram avaliados por meio de uma entrevista feita em dois momentos distintos, com o intuito de se obter 20 crianças com amigos imaginários e a mesma quantidade de crianças sem amigos imaginários. Deste modo, foram coletados dados com 18 crianças que se engajavam na criação de companhias de faz de conta (no momento atual ou anteriormente) e 22 que não se engajavam nessa fantasia. Foi possível entrevistar apenas 11 responsáveis que tiveram disponibilidade para participar. A pesquisa foi aprovada pelo Comitê de Ética em Pesquisa com Seres Humanos da Universidade Federal de São Carlos, conforme o parecer 162.740 (CAAE: 10222112.0.0000.5504), e a participação na pesquisa estava condicionada à apresentação do consentimento por escrito dos pais.

\section{Local e Equipamentos}

A coleta de dados ocorreu nas dependências da escola onde foram recrutados os participantes, em salas bem iluminadas e que contavam com mesa e cadeiras. Uma câmera filmadora e um gravador eram usados para gravar as sessões.

\section{Instrumentos}

Instrumentos utilizados com as crianças. Um roteiro de entrevista sobre fantasia e amigos imaginários era utilizado, bem como três diferentes tarefas de teoria da mente, um teste de vocabulário receptivo e, finalmente, um teste de compreensão de emoções. Os instrumentos são descritos a seguir.

Entrevista sobre fantasia e amigos imaginários. Com base no procedimento utilizado por Taylor e Carlson (1997), 
uma entrevista foi realizada com as crianças a fim de se obter uma medida do nível de engajamento em fantasia, em geral, e verificar a criação de amigos imaginários.

Primeiramente, eram feitas algumas questões que avaliavam o engajamento em fantasia (Imaginative Play Predisposition), conforme o procedimento de Singer (1961). Por exemplo, era perguntado o que a criança gostava de fazer quando estava sozinha, e o que pensava antes de dormir. Em sequência, eram feitas outras perguntas relativas às preferências da criança em relação à história infantil, programa de televisão, brinquedo e brincadeira favorita em grupo, conforme o procedimento de Taylor e Carlson (1997). Deste modo, um conjunto de oito questões abertas compunha uma medida de fantasia.

Por fim, era feita a entrevista específica sobre amigos imaginários, baseada no procedimento utilizado por Taylor e Carlson (1997), e que se iniciava da seguinte forma:

Agora, eu irei fazer algumas perguntas para você sobre os seus amigos. Alguns dos nossos amigos são reais, de 'carne e osso' - que a gente pode ver, tocar, como eu e você. Esses amigos reais são, por exemplo, aqueles que vivem na nossa rua, ou aqueles com os quais a gente brinca na escola. Mas há alguns amigos que são diferentes dos amigos reais, porque eles são de faz de conta, a gente inventa. Esses amigos são chamados de amigos imaginários, porque a gente imagina. Então, os amigos imaginários são aqueles de mentirinha, que a gente faz de conta que existem. Você tem um amigo imaginário?

Caso a criança respondesse positivamente, eram feitas diversas perguntas a fim de caracterizar a criação imaginária. Assim, eram feitas questões sobre: (a) o nome; (b) gênero; (c) a idade; (d) aparência física; (e) se era um brinquedo, ou uma criação totalmente imaginária; (f) onde o amigo imaginário vivia e dormia; (g) o que a criança fazia na companhia dele; e (h) o que a criança gostava e não gostava sobre ele. Algumas questões complementares às elaboradas por Taylor et al. (1993) foram adicionadas (e.g., quando o amigo aparece e vai embora, os conteúdos de suas conversas, quem sabe de sua criação).

A fim de auxiliar na identificação de criações espontâneas feitas durante a sessão, que não se configuravam como amigos imaginários, foi adotado o procedimento de perguntar: (a) "Você já brincou ou conversou com ele (a)?”; (b) “Tenho a impressão que você está me contando de alguém com quem poderia ou gostaria de brincar e conversar, é isso?".

Avaliação de vocabulário receptivo. $\mathrm{O}$ Teste de Vocabulário por Imagens Peabody (TVIP) é um instrumento traduzido e padronizado no Brasil por Capovilla e colaboradores (Capovilla \& Capovilla, 1997), que mede o vocabulário receptivo de crianças e adolescentes. A aplicação consiste em apresentar uma folha da apostila de cada vez e solicitar à criança que aponte a imagem, ou diga o número correspondente à figura que representa a palavra que for dita pelo pesquisador. No total, são 125 palavras, entre substantivos, adjetivos e verbos. Para cada idade, há um item correspondente para início do teste e o critério para encerramento é a criança cometer seis erros em uma sequência de oito respostas consecutivas.

Tarefas de teoria da mente. Três tarefas que avaliam componentes diferentes da teoria da mente foram utilizadas: (a) crença-emoção; (b) emoção real e aparente; e (c) tarefa de crença falsa de segunda ordem. As duas primeiras proveem da escala de teoria da mente para crianças, criada por Wellman e Liu (2004), que avalia sete aspectos diferentes da compreensão de mente. As tarefas selecionadas consistem nas duas tarefas mais difíceis do instrumento, o que se justifica por ser esperado que as anteriores sejam demasiado fáceis para crianças da faixa etária dos participantes.

A tarefa de crença e emoção tem como objetivo verificar se a criança compreende que as emoções estão associadas às crenças das pessoas e que, portanto, quando uma pessoa tem uma expectativa (e.g., bombons), irá ficar triste ao descobrir que o conteúdo de uma caixa é outro (e.g., pedras). Por sua vez, a tarefa de emoção real e aparente tem por objetivo avaliar se o participante entende que uma pessoa pode aparentar sentir uma emoção, quando na verdade sente outra - ou seja, esconder que está triste. Seguindo Pavarini e Souza (2010), foram utilizados desenhos adicionais que representavam momentos distintos da narrativa, nos quais o personagem principal aparecia sempre de costas para o expectador, além de uma folha que apresentava o rosto do mesmo, com três expressões faciais diferentes (feliz, triste e neutra). Em ambas as tarefas, o critério de justificar as respostas foi adotado. Uma tarefa de crença falsa de segunda ordem foi incluída por ser ainda mais complexa que as duas primeiras tarefas utilizadas na pesquisa. Desenvolvida por Astington, Pelletier e Homer (2002), a tarefa tem por objetivo verificar se a criança consegue identificar a crença falsa que uma pessoa tem a respeito da crença de uma terceira pessoa.

Teste de Compreensão de Emoçães (TCE). Desenvolvido por Pons e Harris (2000), traduzido e validado para o Brasil por Minervino, Roazzi, Dias e Roazzi (2010), o teste permite analisar o desenvolvimento da competência emocional em crianças, por meio de nove fatores correspondentes aos componentes emocionais (e.g., expressão facial das moções; as suas causas situacionais externas, a relação entre o errado e a culpa). O teste consiste, inicialmente, em avaliar o reconhecimento de emoções, com base nas expressões faciais e, posteriormente, em ler narrativas simples para a criança e solicitar que ela selecione a imagem do livro ilustrado que representa a emoção adequada ao contexto. O participante recebe um ponto por acerto, podendo obter escores de 0 a 9 pontos.

Instrumentos utilizados com os pais. Um roteiro foi utilizado para entrevistar os responsáveis pelas crianças, e consistiu em: (a) questões sobre a família e a criança; e uma (b) entrevista sobre amigos imaginários. Inicialmente, pretendia-se realizar as entrevistas com todos os pais de 
crianças participantes, mas isso não foi possível pelas seguintes razões: (a) não foram obtidos os contatos telefônicos de todos os responsáveis, conforme foi solicitado por escrito; (b) diversas crianças autorizadas utilizavam o transporte escolar e, portanto, a pesquisadora não conseguiu ter um contato presencial com os pais; (c) muitos pais não podiam se apresentar na escola para a entrevista em dia de semana, durante o horário comercial; (d) mesmo quando entrevistas presenciais eram marcadas, era frequente os pais desmarcarem ou faltarem ao compromisso. Diante de tais dificuldades, foi decidido realizar entrevistas não-presenciais, via telefone.

Dados sobre a família, a criança, suas brincadeiras e preferências. Tomando como referência os procedimentos de Taylor e Carlson (1997) e Manosevitz et al. (1973), algumas perguntas abertas foram feitas a fim de caracterizar a família da criança, parceiros de brincadeira, brinquedos possuídos, preferências por atividades, além de investigar se a criança já havia apresentado problemas de comportamento ou emocionais, e se já havia passado por tratamento psiquiátrico ou psicoterápico.

Entrevista sobre amigos imaginários. A pesquisadora perguntava aos pais se eles se lembravam de algum episódio durante o qual a criança havia mencionado ter um amigo imaginário. As mesmas perguntas complementares utilizadas com as crianças eram feitas àqueles que relataram conhecimento sobre algum amigo imaginário do filho/ da filha.

\section{Procedimentos}

No momento da realização das sessões, a criança era conduzida à sala de coleta de dados pela experimentadora. As atividades foram realizadas individualmente com os participantes, durando aproximadamente 30 minutos. Os instrumentos foram utilizados na seguinte ordem: entrevista sobre amigos imaginários e fantasia, TVIP, tarefas de teoria da mente e TCE. Ao todo, foram realizadas três a cinco sessões com cada participante, a depender do tempo disponível para a coleta de dados. No último encontro, era feita uma nova entrevista sobre amigos imaginários, independentemente de a criança ter relatado criar companhias de faz de conta anteriormente. O intervalo entre a primeira e a última sessão variou de algumas horas (apenas um caso) a um mês e meio.

As entrevistas com os responsáveis foram feitas parte presencialmente, em um horário conveniente para a diretoria da escola e os responsáveis, e parte via telefone. No caso das entrevistas via telefone, era utilizado o recurso de "viva voz" do aparelho, de modo que o som pudesse ser captado pelo gravador. O roteiro de entrevista destinado aos pais era seguido conforme a ordem em que os instrumentos se encontram.

Medida de confiabilidade. A fim de obter uma medida de confiabilidade quanto à análise das funções dos amigos imaginários, uma amostra de $22 \%(\mathrm{n}=4)$ dos dados das entrevistas (áudios e/ou vídeos) das crianças com companhias de faz de conta foram analisados e codificados por um segundo juiz e comparados com a avaliação realizada pela experimentadora. Para tanto, foi calculada a estatística Kappa de Cohen, uma medida de concordância interobservador, que avalia o grau de concordância além do esperado pelo acaso. O coeficiente de confiabilidade obtido foi $k=0,56, p=0,08$, considerado moderado (Landis \& Koch, 1977).

\section{RESULTADOS}

Como reportado anteriormente, das 40 crianças que participaram do estudo, 18 participantes (45\%) formaram o grupo com amigos imaginários (AI) e 22 participantes (55\%) o grupo sem amigos imaginários (SAI). Entre as crianças com amigos imaginários, 13 crianças $(72,2 \%)$ relataram possuir companhias imaginárias atualmente, em idade escolar, três $(16,3 \%)$ possuíam AI desde a educação infantil e duas $(15,4 \%)$ haviam criado companhias apenas durante os anos da educação infantil.

Em relação ao número de amigos imaginários, 12 crianças $(66,6 \%)$ disseram ter tido um único amigo imaginário estável até aquele momento, enquanto três participantes $(16,6 \%)$ relataram possuir mais de dois amigos imaginários permanentes. As três crianças restantes $(16,6 \%)$ relataram que inventavam sempre novas companhias e que elas nunca se repetiam. De todas essas criações, há apenas dois casos de projeção em objetos de apoio, que eram brinquedos. Entre todas as criações, $13(72,2 \%)$ eram figuras humanas, enquanto quatro $(22,2 \%)$ eram criações de ficção (super-heróis e personagens de gibi ou desenho) e outra (5,5\%) era um animal (gato). Em geral, o gênero dos amigos era compatível com o das próprias crianças, com a exceção de uma participante.

A fim de verificar a normalidade da distribuição dos escores nas medidas de TM, TCE, TVIP e engajamento em fantasia, em relação a status de amigo imaginário, testes Kolmogorov-Smirnov foram realizados. A distribuição dos escores obtidos no TVIP se mostraram normais tanto para o grupo $\mathrm{SAI}\left(D_{(22)}=0,07, p>0,05\right)$, quanto para o $\mathrm{AI}\left(D_{(18)}\right.$ $=0,14, p>0,05)$. Em relação ao TCE, mais uma vez, a distribuição dos escores era normal para os grupos $\mathrm{SAI}\left(D_{(22)}\right.$ $=0,18, p>0,15)$ e $\mathrm{AI}\left(D_{(18)}=0,20, p>0,05\right)$. Por sua vez, a distribuição dos escores de TM não se mostrou normal para o grupo $\operatorname{SAI}\left(D_{(22)}=0,26, p=0,001\right)$, assim como para o AI $\left(D_{(18)}=0,31, p<0,001\right)$. Finalmente, as distribuições dos 
escores obtidos em engajamento em fantasia pelos grupos SAI $\left(D_{(22)}=0,21, p>0,05\right)$ e AI $\left(D_{(18)}=0,19, p>0,05\right) \mathrm{se}$ mostraram normais.

Considerando os resultados dos testes K-S, testes paramétricos foram utilizados para avaliar os escores em
TVIP, TCE e engajamento em fantasia. Por sua vez, um teste não-paramétrico foi utilizado para analisar possíveis diferenças em TM. A Tabela 1 apresenta os escores médios obtidos por cada grupo (SAI e AI) nas medidas de TM, TCE, TVIP e engajamento em fantasia.

Tabela 1

Média e Desvio Padrão, por Status de Amigo Imaginário, para cada Medida

\begin{tabular}{clll}
\hline \multirow{2}{*}{ Teoria da Mente } & Status & M & DP \\
\hline \multirow{2}{*}{ Compreensão de Emoções } & Sem AI & 2,18 & 0,17 \\
\cline { 2 - 4 } & Com AI & 2,28 & 0,19 \\
\cline { 2 - 4 } & Sem AI & 5,73 & 0,32 \\
\hline \multirow{2}{*}{ Vocabulário Receptivo } & Com AI & 6,32 \\
\cline { 2 - 4 } Engajamento em Fantasia & Sem AI & 6,28 & 1,97 \\
\cline { 2 - 4 } & Com AI & 7,79 \\
\hline \multirow{2}{*}{ Sem AI } & 14,89 & 0,20 \\
\hline
\end{tabular}

Nota. As variações possiveis de pontuação, para cada medida, foram: (a) TM, de 0 a 3 pontos; (b) TCE, de 0 a 9 pontos; (c) TVIP, até 124 pontos; (d) engajamento em fantasia, de 8 a 16 pontos.

Um teste de Mann-Whitney foi conduzido a fim de avaliar possíveis associações entre status de amigo imaginário e teoria da mente. Não foram encontradas diferenças significativas entre os dois grupos em TM ( $U$ $=183,5, p>0,05, r=-0,07)$. O grupo com AI obteve um escore médio de $2,28(D P=0,19)$, enquanto o grupo que não criava tais companhias obteve uma pontuação média de $2,18(D P=0,17)$. Testes $t$ foram realizados a fim de se verificar possíveis diferenças entre os dois grupos em relação às seguintes variáveis: vocabulário receptivo, compreensão emocional e engajamento em fantasia. Não foram encontradas diferenças significativas entre os dois grupos com relação aos escores obtidos no TCE $(t(38)=$ $-1,11, p>0,05)$ e engajamento em fantasia $(t(38)=0,74$, $p>0,05)$. No entanto, uma diferença significativa foi encontrada em relação aos escores de $\operatorname{TVIP}(t(38)=-2,10$, $p=0,042)$, sendo que as crianças com AI obtiveram escores mais elevados do que as crianças sem AI.

\section{DISCUSSÃO}

De modo geral, os resultados do presente estudo parecem convergir com a literatura estrangeira, tanto em relação às características dos amigos imaginários, como na ausência de associação com atrasos ou desvantagens em desenvolvimento. Em especial, os dados parecem confirmar os achados de estudos prévios internacionais de que a criação de $\mathrm{AI}$ não se limita à primeira infância e é um fenômeno frequente durante a idade escolar (Bouldin \& Pratt, 2001; Hoff, 2005b; Mathur \& Smith, 2008; Taylor et al., 2004).

De fato, 18 crianças com amigos imaginários foram encontradas por meio de uma triagem inicial realizada com 58 crianças (31\%). Por exemplo, os dados de Taylor et al. (2004) indicaram que, entre os 6 e os 7 anos, $31 \%$ das crianças estavam se engajando na criação de AI no presente, mas que $65 \%$ das crianças haviam criado tais companhias até os 7 anos. Finalmente, Hoff (2005b) sugere que mesmo crianças mais velhas continuam a ter companhias imaginárias, já que com uma amostra cuja faixa etária era 9 a 10 anos de idade, $38 \%$ relataram ter AI no tempo atual, enquanto $52 \%$ haviam tido até aquele momento (presente ou passado).

Em relação à natureza das criações de faz de conta das crianças brasileiras, os dados mostraram uma riqueza muito grande e características muito diversas entre os amigos imaginários dos participantes, o que parece corroborar os dados de estudos estrangeiros. Taylor, Carlson e Shawber (2008) relatam ter coletado centenas de descrições de AI em suas pesquisas e terem se surpreendido com a diversidade das criações, que é indicativa de que não há um AI prototípico. Efetivamente, alguns relatos de AI incluíram desde um gatinho que gosta de brincar, até versões de fantasia de amigos reais e criaturas com superpoderes.

Ao comparar os grupos de crianças com e sem AI, ao contrário do esperado, as análises estatísticas indicaram não haver diferenças entre os grupos em relação à teoria da mente $\mathrm{e}$ à compreensão de emoções. Os dados da literatura, no entanto, não são consensuais. Taylor e Carlson (1997) encontraram uma associação positiva entre o desenvolvimento da teoria da mente e alta fantasia (i.e., criação de companhias de fantasia ou personificação), aos 4 anos.

Em outros dois estudos (Davis et al., 2011; Fernyhough et al., 2007), a associação entre teoria da mente e status de amigo imaginário mostrou-se ausente. De fato, as medidas utilizadas para se avaliar teoria da mente foram distintas nas três pesquisas. Enquanto Taylor e Carlson (1997) utilizaram quatro tarefas padrão de teoria da mente, Davis et al. empregaram a escala de teoria da mente (Wellman \& Liu, 
2004), e Fernyhough et al. (2007) utilizaram um teste que avaliava a habilidade de compreender que a consciência se mantém, mesmo na ausência de dicas perceptuais externas.

Os estudos de Taylor e colegas sugerem que, aos 4 anos, $o$ alto engajamento em fantasia (i.e., AI ou personificação) se correlaciona a melhores performances em testes padrão em teoria da mente e que, aos 7 anos, o desempenho em uma medida de compreensão de emoções se correlaciona apenas ao engajamento em personificação - e não à criação de amigos imaginários (Taylor et al., 2004). De todo modo, as médias obtidas no Teste de Compreensão Emocional (TEC) pelos dois grupos (com AI x sem AI) indicaram uma pequena vantagem para aqueles que criam companhias imaginárias, mas a diferença não é significativa. É possível que o referido efeito aparecesse se a amostra fosse maior.

Os dados do presente estudo apontam para a ausência de uma associação entre teoria da mente e a criação de companhias imaginários, em idade escolar, o que é consistente com os achados de Davis et al. (2011) e Fernyhough et al. (2007). Uma possível explicação para essa falta de convergência está relacionada, mais uma vez, à faixa etária utilizada nos diferentes estudos. No presente trabalho, optou-se por coletar dados com crianças de 6 e 7 anos, a fim de colaborar com a literatura sobre a criação de companhias imaginárias em idade escolar e porque esperava-se que os relatos providos sobre fantasia fossem mais ricos nessa faixa etária. Uma explicação alternativa é a de que uma possível vantagem em teoria da mente para as crianças com AI estaria presente apenas em crianças mais novas, entre 4 e 5 anos, quando os avanços mais significativos em desenvolvimento sociocognitivo ocorrem.

Ao mesmo tempo, a escolha das tarefas de teoria da mente foi feita com base na faixa etária dos participantes. A literatura indica que as três tarefas selecionadas (crençaemoção, emoção real e aparente e tarefa de crença falsa de segunda ordem) seriam difíceis para as crianças de 6 anos, ainda assim, até mesmo três participantes dessa faixa etária completaram os três pontos possíveis na medida de teoria da mente. É possível também que a inclusão de dicas visuais e dicas verbais na adaptação da última tarefa, utilizada no presente estudo, possa ter facilitado o comportamento de discriminar as emoções e, assim, contribuído para o bom desempenho dos participantes.

No estudo de Pavarini e Souza (2010), o desempenho das crianças foi, de fato, melhor com o auxílio de tais figuras, quando comparado com a versão original da tarefa que inclui apenas um desenho em preto e branco e pouca informação visual. As possíveis dicas verbais, por sua vez, seriam a inclusão dos termos por dentro e por fora, nas questões-teste. É importante lembrar, entretanto, que as dicas linguísticas são usadas apenas para explicitar a intenção do experimentador para o participante, ou seja, tornar o conteúdo da pergunta mais facilmente compreensível, não indicando, entretanto, qual a resposta correta. Mais pesquisas brasileiras testando uma versão padronizada e validada da escala de teoria da mente (Wellman \& Liu, 2004) são necessárias para produzir o controle experimental desejado.

Confirmando a hipótese inicial, a criação de amigos imaginários se correlacionou positivamente com a medida de linguagem receptiva, sugerindo que o fenômeno se associa a uma linguagem mais desenvolvida, conforme os dados de Davis et al. (2011). Cabe ressaltar que a literatura indica que o fenômeno se associa, ainda, a outras habilidades verbais, como uma linguagem mais sofisticada (Bouldin et al., 2002), habilidades comunicativas referenciais mais desenvolvidas (Roby \& Kidd, 2008) e uma maior habilidade narrativa (Trionfi \& Reese, 2009).

Os achados de Bouldin et al. (2002) indicam que as crianças que possuem companhias imaginárias apresentam um padrão de discurso mais maduro do que os seus pares de mesma idade que não se engajam nessa fantasia - ou seja, emprego significativamente mais frequente de pronomes adverbiais e relativos, além das conjunções $e$ e mas. Segundo a literatura, há habilidades linguísticas que dependem não apenas de conhecimento conceitual, mas também da maturação de habilidades sociocognitivas. Além disso, o maior emprego de pronomes relativos indica que as crianças proveem informações adicionais a fim de colaborar com o ouvinte, sugerindo uma maior sensibilidade às necessidades do interlocutor (cf. Bouldin et al., 2002).

Bouldin et al. (2002) teorizam que o fato de as crianças tratarem a companhia imaginária como um indivíduo à parte pode auxiliar no desenvolvimento da habilidade de regulação da comunicação, já que as mesmas interagem frequentemente com a sua criação e, assim, podem se beneficiar desde contexto social de fantasia para exercitar as suas habilidades verbais.

Segundo Taylor (1999), as crianças que possuem amigos imaginários estão cientes que os outros não podem ter acesso direto às suas criações, portanto, é apenas por meio da fala e do comportamento que elas possibilitam que as pessoas ao seu redor tomem conhecimento sobre as suas companhias de faz de conta. Davis et al. (2011) sustentam que as crianças que se engajam nessa fantasia possuem mais oportunidades de aprender que os estados mentais são privados, assim como de praticar julgamentos sobre estados de conhecimento (eu versus outros) sobre o seu mundo interno.

Os achados de Roby e Kidd (2008) sobre comunicação referencial parecem corroborar o achado de Davis et al. (2011), já que as crianças com amigos imaginários se saem melhor que o grupo comparação em tarefas que requerem descrever figuras a terceiros que não têm acesso às mesmas. Os autores afirmam que o sucesso em tais tarefas depende da habilidade de tomada de perspectiva, a qual também é requerida nas tarefas padrão de teoria da mente.

Finalmente, os resultados de Trionfi e Reese (2009) indicam uma clara correlação entre ter amigos imaginários e habilidade narrativa mais desenvolvida. Os autores especulam que a razão para tanto seria que tais crianças praticam conversas descontextualizas, tanto quando 
interagem com as suas criações imaginárias, como quando relatam a terceiros sobre as mesmas. É possível que durante os episódios de narração a adultos, como seus pais e outros membros da família, seus interlocutores mais experientes promovam o engajamento e compreensão de práticas linguísticas descontextualizadas complexas. Deste modo, a prática rotineira de tais conversas resulta em habilidades narrativas mais desenvolvidas.

É interessante retomar nessa discussão que as crianças que se engajam nesse faz de conta peculiar tendem a ser indivíduos sociáveis (Gleason, 2002; Hoff, 2005a; Manosevitz et al., 1973), que buscam ativamente contato social. Nesses intercursos com pares e falantes mais experientes, elas podem obter ganhos em habilidades linguísticas e vocabulário que, por sua vez, são exercitados não apenas em contextos sociais, como em suas brincadeiras com entidades imaginárias, frutos de sua criação, como sugerem Bouldin et al. (2002) e Trionfi e Reese (2009).

Como pode ser observado, a literatura sugere diversas explicações para as associações entre a criação de amigos imaginários e o desenvolvimento da linguagem, no entanto, tais propostas ainda precisam ser mais bem investigadas em estudos futuros.

Finalmente, contrariamente ao esperado, a medida de engajamento em fantasia não se correlacionou com o status de AI. Diversos estudos indicam que a criação de companhias imaginárias está associada a uma maior quantidade de brincadeira espontânea e a uma maior tendência ao engajamento em faz de conta, em geral (Bouldin, 2006, Bouldin \& Pratt, 2001, Mathur \& Smith,
2008; Singer, 1961; Taylor, 1999; Taylor et al., 1993). É possível que a medida utilizada não tenha sido a ideal, até porque não houve nenhuma medida além da entrevista sobre engajamento em brincadeira imaginativa e preferências. Por exemplo, o estudo de Taylor \& Carlson (1997) utilizou uma medida composta, que incluía uma entrevista com a criança e os pais, e continha mais de uma medida comportamental.

Uma das limitações do presente estudo é não apresentar dados com crianças em idade pré-escolar, as quais seriam particularmente interessantes em uma investigação sobre a possível associação entre status de amigo imaginário e cognição social. De acordo com Taylor e Carlson (1997), o período entre os 3 e os 4 anos é marcado por um considerável desenvolvimento nas performances infantis em testes padrão de teoria da mente, o que o torna ideal para o estudo da relação pretendida. Considerando-se a diversidade de faixas etárias e medidas utilizadas nos estudos que avaliavam a associação entre compreensão social e amigos imaginários, e as reflexões sobre variância, sugere-se a investigação da mesma em crianças pré-escolares, empregando-se a escala completa de teoria da mente (Wellman \& Liu, 2004).

Finalmente, cabe considerar que outro fator limitante do presente estudo foi a restrição da variação das medidas realizadas, já que com exceção da medida de linguagem receptiva, as de teoria da mente, compreensão emocional e engajamento em fantasia, apresentavam pouca variância, sendo uma explicação possível para a dificuldade em encontrar diferenças entre os grupos com e sem amigos imaginários. $\mathrm{O}$ ideal, portanto, é que as medidas utilizadas apresentem uma maior variação.

\section{CONSIDERAÇÕES FINAIS}

Conforme Taylor et al. (2009) afirmam, a invenção de amigos imaginários é somente uma das diversas formas que a fantasia infantil pode assumir. De forma semelhante, a literatura indica um grande número de associações entre o fenômeno e habilidades várias, seja durante a infância (e.g., linguagem receptiva, no presente estudo), adolescência (e.g., competência social, criatividade, habilidades de enfrentamento), ou vida adulta (e.g., imaginação). Portanto, a criação de amigos imaginários parece contribuir ou estar associada a diferentes habilidades e ter diferentes funções, em momentos distintos da vida.

Apesar das limitações apontadas, o presente trabalho traz uma contribuição importante para esse campo de estudos e, de um modo mais abrangente, para a Psicologia Brasileira ao oferecer evidências de que a criação de amigos imaginários não se associa a déficits em desenvolvimento. Confirmando os dados da literatura psicológica mais recente acerca do fenômeno (cf. Taylor et al., 2009), as crianças que possuem amigos imaginários são crianças típicas, que não apresentam desvantagens em cognição social, e podem inclusive apresentar habilidades mais sofisticadas - no presente trabalho, um vocabulário receptivo mais desenvolvido.

Tomando uma perspectiva de desenvolvimento ao longo da vida, propõe-se que, embora a criação de amigos imaginários seja comumente abandonada ainda durante a infância (Taylor, 1999), a sua contribuição permanece, no sentido de auxiliar na aprendizagem e consolidação de habilidades sociocognitivas várias, como atesta a literatura. Propõe-se, portanto, que pesquisas e estudos futuros procurem contribuir para um modelo integrador, que considere as diferentes etapas do desenvolvimento humano. 


\section{REFERÊNCIAS}

Astington, J. W., \& Hughes, C. (2013). Theory of mind: Selfreflection and social understanding. In P. D. Zelazo (Ed.), The Oxford handbook of developmental psychology (398-424). New York: Oxford University Press.

Astington, J. W, \& Jenkins, J. M. (1995). Theory of mind development and social understanding. Cognition and Emotion, 9(2-3), 151-165. doi: 10.1080/02699939508409006

Astington, J., Pelletier, J., \& Homer, B. (2002). Theory of mind and epistemological development: The relation between children's second order understanding and their ability to reason about evidence. New Ideas in Psychology, 20, 131-144.

Bittencourt, C. M., \& Blanco, D. C. (1996). O amigo imaginário na percepção das mães. Psico, 27(2), 139-151.

Bouldin, P. (2006). An investigation of the fantasy predisposition and fantasy style of children with imaginary companions. The Journal of Genetic Psychology, 167(1), 17-29. doi: 10.3200/ GNTP.167.1.17-29

Bouldin, P., Bavin, E. L., \& Pratt, C. (2002). An investigation of the verbal abilities of children with imaginary companions. First Language, 22, 249-264. doi: 10.1177/014272370202206602

Bouldin, P., \& Pratt, C. (2001). The ability of children with imaginary companions to differentiate between fantasy and reality. British Journal of Developmental Psychology, 19, 99-114.

Capovilla, F. C., \& Capovilla, A. G. S. (1997). Desenvolvimento linguístico na criança dos dois aos seis anos: Tradução e estandardização do Peabody Picture Vocabulary Test de Dunn \& Dunn, e da Language Development Survey de Rescorla. Ciência Cognitiva: Teoria, Pesquisa e Aplicação, 1, 353-380.

Carpendale, J., \& Lewis, C. (2006). How children develop social understanding. Oxford: Blackwell Publishers.

Davis, P., Paige, E., Meins, E., \& Fernyhough, C. (2011). Selfknowledge in childhood: Relations with children's imaginary companions and understanding of mind. British Journal of Developmental, 29(3), 680-686. doi: 10.1111/j.2044835X.2011.02038.x

Fernyhough, C., Bland, K., Meins, E., \& Coltheart, M. (2007). Imaginary companions and young children's responses to ambiguous auditory stimuli: Implications for atypical development. Journal of Child Psychology and Psychiatry, 48(11), 1094-1101. doi:10.1111/j.1469-7610.2007.01789.x

Gleason, T. R. (2002). Social provisions of real and imaginary relationships in early childhood. Developmental Psychology, 38(6), 979-992. doi: 10.1037/0012-1649.38.6.979

Gleason, T. R (2004). Imaginary companions: An evaluation of parents as reporters. Infant and Child Development, 13, 199-215. doi: 10.1002/icd.349

Gleason, T. R., Jarudi, R. N., \& Cheek, J. M. (2003). Imagination, personality, and imaginary companions. Social Behavior and Personality, 31(7), 721-738. doi: 10.2224/sbp.2003.31.7.721

Harris, P. L. (2000). The work of the imagination. Oxford: Blackwell Publishers.

Harris, P. L. (2006). Social cognition. In W. Damon, R. Lerner, D. Kuhn \& R. Siegler (Eds), Handbook of child psychology

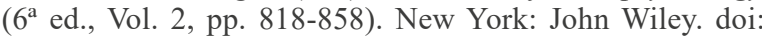
10.1002/9780470147658.chpsy0219

Hoff, E. V. (2005a). A friend living inside me - The forms and functions of imaginary companions. Imagination, Cognition and Personality, 24, 151-189. doi: 10.2190/4M9J-76M24Q4Q-8KYT

Hoff, E. V. (2005b). Imaginary companions, creativity, and selfimage in middle childhood. Creativity Research Journal, 17(23), 167-180. doi: 10.1080/10400419.2005.9651477

Jenkins, J. M., \& Astington, J. W. (2000). Theory of mind and social behavior: Causal models tested in a longitudinal study. Merrill-Palmer Quarterly, 46, 203-220
Landis, J. R., \& Koch, G. G. (1977). The measurement of observer agreement for categorical data. Biometrics, 33, 159-174.

Manosevitz, M., Prentice, N., \& Wilson, F. (1973). Individual and family correlates of imaginary companions in preschool children. Developmental Psychology, 8, 72-79. doi: $10.1080 / 01650250344000415$

Mathur, R, \& Smith, M. C. (2008). An investigation of imaginary companions in an ethic and grade diverse sample. Imagination, Cognition and Personality, 27(4), 313-336. doi: 10.2190/ IC.27.4.c

Minervino, C. A. S. M., Roazzi, A., Dias, M. G. B. B., \& Roazzi, M. (2010). In M. C. R. A Joly \& C. T. Reppold (2010). Testes informatizados para a avaliação psicológica e educacional. E-book. São Paulo: Casa do Psicólogo.

Pavarini, G., \& Souza, D. H. (2010) Teoria da mente, empatia e motivação pró-social em crianças pré-escolares. Psicologia em Estudo, 15(3), 613-622.

Pons, F., \& Harris, P. L. (2000). TEC (Test of Emotion Comprehension). Oxford, UK: Oxford University Press.

Preissler, M. A. (2006). Play and autism: Facilitating symbolic understanding. In D. G. Singer, R. M. Golinkoff \& K. HirshPasek (Eds.), Play = learning: How play motivates and enhances children's cognitive and socio-emotional growth (pp. 231-250). New York: Oxford University Press. doi: 10.1093/ acprof:oso/9780195304381.003.0012

Roby, A. C., \& Kidd, E. (2008). The referential communication skills of children with imaginary companions. Developmental Science, 11(4), 531-540. doi: 10.1111/j.1467-7687.2008.00699.x

Singer, J. L. (1961). Imagination and waiting ability in young children. Journal of Personality, 29(4), 396-413. doi: 10.1111/ j.1467-6494.1961.tb01670.

Seiffge-Krenke, I. (1997). Imaginary companions in adolescence: Sign of a deficient or positive development? Journal of Adolescence, 20, 137-154. doi: 10.1080/01650250344000415

Smith, P. K. (2002). Pretend play, metarepresentation and theory of mind. In R. W. Mitchell (Ed), Pretending and imagination in animals and children. Cambridge: Cambridge University Press. doi: 10.1017/CBO9780511542282.011

Sperb, T. M., \& Carraro, L. (2008). A relação entre o faz-de-conta e a teoria da mente: Controvérsias teóricas e empíricas. In T. M. Sperb \& M. R. Maluf(Eds.), Desenvolvimento sociocognitivo: Estudos brasileiros sobre "teoria da mente". (pp. 163-190). São Paulo, SP: Vetor.

Tavares, L. C., \& Pinheiro, M. L. (1989). O amigo imaginário. Psico, 17(1), 150-163.

Taylor, M. (1999). Imaginary companions and the children who create them. Melbourne: Oxford University Press.

Taylor, M., \& Carlson, S. M. (1997). The relation between individual differences in fantasy and theory of mind. Child Development, 68(3), 436-455. doi: 10.1111/j.1467-8624.1997.tb01950.x

Taylor, M., \& Carlson, S. M. (2000). The influence of religious beliefs on parental attitudes about children's fantasy behavior. In K. S. Rosengreen, C. N. Johnson \& P. L. Harris (Eds.), Imagining the impossible: Magical, scientific, and religious thinking in children (pp. 227-245). Cambridge: Cambridge University Press. doi: 10.1017/CBO9780511571381.010

Taylor, M., Carlson, S. M., Maring, B., Gerow, L., \& Charley, C. M. (2004). The characteristics and correlates of fantasy in school-age children: Imaginary companions, impersonation, and social understanding. Developmental Psychology, 40, 1173-1187. doi: 10.1037/0012-1649.40.6.1173

Taylor, M., Carlson, S. M., \& Shawber, A. B. (2008). Autonomy and control in children's interactions with imaginary companions. In I. Roth (Ed.), Imaginative minds (pp. 80-100). Cambridge: Cambridge University Press. 
Taylor, M., Cartwright, B. S., \& Carlson, S. M. (1993). A developmental investigation of children's imaginary companions. Developmental Psychology, 29, 276-285. doi: 10.1037/0012-1649.29.2.276

Taylor, M., Hulette, A. C., \& Dishion, T. J. (2010). Longitudinal outcomes of young high-risk adolescents with imaginary companions. Developmental Psychology, 46, 1632-1636. doi: 10.1037/a0019815

Taylor, M., \& Mannering, A. M. (2007). Of Hobbes and Harvey: The imaginary companions of children and adults. In A. Goncu \& S. Gaskins (Eds.), Play and development: Evolutionary, sociocultural and functional perspectives (pp. 227-245). Mawah, NJ: Erlbaum Press.

Taylor, M., \& Mottweiler, C. M. (2008). Imaginary companions: Pretending they are real but knowing they are not. American Journal of Play, 1, 47-54.

Taylor, M., Shawber, A. B., \& Mannering, A. M. (2009). Children's imaginary companions: What is it like to have an invisible friend? In K. D. Markman, W. M. P. Klein \& J. A. Suhr (Eds.), Handbook of imagination and mental simulation (pp. 211-224). New York, NY: Psychology Press.
Trionfi, G., \& Reese, E. (2009). A good story: Children with imaginary companions create richer narratives. Child Development, 80(4), 1301-1313. doi: 10.1111/j.14678624.2009.01333.x

Velludo, N. B., \& Souza, D. H. (2015). A criação de amigos imaginários: Uma revisão de literatura. Psico, 46(1), 25-37. doi: 10.15448/1980-8623.2015.1.16406

Wellman, H. M., \& Liu, D. (2004). Scaling of theory-of-mind tests. Child Development, 75(2), 523-541. doi: 10.1111/j.14678624.2004.00691.x

Youngblade, L. M., \& Dunn, J. (1995). Individual differences in young children's pretend play with mother and sibling: Links to relationships and understanding of other people's feelings and beliefs. Child Development, 66, 1472-1492. doi: 10.1111/j.1467-8624.1995.tb00946.x

Recebido em: 25/06/2015 Aceito em: 22/03/2016 